\title{
Raça, democracia racial e racismo
}

\section{Gabriel Siqueira}

Mestrando no (PPFH UERJ).gabrielsiqueira19@hotmail.com

\section{Resumo}

O presente artigo trata de assunto polêmico que tem sido tratado pelos veículos de comunicação, contudo nem sempre com rigor científico. O tema da raça, democracia racial e racismo no é discutido neste artigo sobre uma literatura clássica nacional que caminha desde 1970 com Clóvis Moura, Abdias do Nascimento e Darcy Ribeiro até os anos mais recentes com produções de Lilia Schwarcz e Hédio Silva Júnior. A partir destes autores trataremos dos conceitos acima descritos com um recorte para o acesso ao Ensino Superior. Palavras-chave: Raça; Racismo; Democracia Racial.

\section{Abstract}

This article discusses controversial subject that has been treated by the media, but not always with scientific rigor. The topic of race, racial democracy and racism is discussed in this article from a brazilian classical literature since 1970 with Clovis Moura, Abdias do Nascimento and Darcy Ribeiro to the recent years with productions of Lilia Schwarcz and Hédio Silva Júnior. From these authors we treat the concepts above, featuring the access to higher education. Keywords: Race; Racism; Racial democracy.

\section{Resumen}

Este artículo aborda a un tema controvertido que ha sido tratado por los medios de comunicación, pero no siempre con rigor científico. El tema de la raza, democracia racial y el racismo se discute en este artículo sobre una literatura clásica brasileña que camina desde 1970 con Clovis Moura, Abdias do Nascimento y Darcy hasta com producciones de los últimos años de Lilia Schwarcz y David Silva Júnior. De estos autores tratan los conceptos descritos anteriormente con un corte para el acceso a la educación superior.

Palabras-claves: Raza; Racismo; Democracia racial. 


\section{Breve introdução}

O presente artigo aborda os aspectos teóricos relativos ao conceito de raça, que, de uma maneira ou de outra, está presente nas formulações das políticas de ações afirmativas, no modelo de cotas. A discussão a ser realizada centra-se no conceito de raça no Brasil, neste caso a discussão raça/cor, conforme sugere o Instituto Brasileiro de Geografia e Estatística (IBGE), além disso, com uma leitura e releitura de autores como Abdias Nascimento (1980), Oracy Nogueira (1985), Kabengelê Munanga (1999), Hédio Silva Júnior (2002) e Darcy Ribeiro (2006).

Diante desta proposta, vamos nos debruçar ainda em conceitos como racialismo e racismo sobre algumas perspectivas teóricas também desenhadas por Abdias Nascimento (1978), Kabenguelê Munanga (2006), Clóvis Moura (1989), Florestan Fernandes (2008) e L. Schwarcz (1987) e (2002).

\section{Uma leitura e releitura de conceitos}

Este é um assunto que permeia a discussão sobre as políticas afirmativas no país. Ainda que de maneira não dita, o debate da democracia racial tem orientado teses, programas de TV e rádio com o tema das ações afirmativas, nesse sentido esta pesquisa se aproveita de toda uma discussão anteriormente acumulada em níveis nacionais e internacionais feitas por diversos autores, cujas obras serão citadas e utilizadas neste capítulo.

As referências teóricas, antes de avançarmos sobre o debate da presença de negros nas universidades brasileiras, nos levam à discussão sobre o conceito de raças, que de uma maneira ou de outra, está presente nas formulações das políticas de ações afirmativas, no modelo de cotas. Diante desta proposta, vamos nos debruçar sobre algumas perspectivas teóricas principais, dentre elas estão Abdias Nascimento, Kabenguelê Munanga, Clóvis Moura e Florestan Fernandes.

Abdias Nascimento é um dos idealizadores das políticas afirmativas no país, baseadas em ações compensatórias para com a população negra. É preciso compreender que tais propostas não nascem de um dia para o outro da cabeça genial de Abdias, sobretudo advém das formulações teóricas que ele se debruçou durante anos desde as contribuições de marxistas e pan-africanistas do movimento negro norte-americano e das lutas de descolonização do continente africano.

De certo modo, a produção de Abdias surge a partir da experiência do intelectual como testemunha da história de representação do negro brasileiro e ator político nacional. Uma produção que gera questionamentos proveitosos para a agenda sobre política e pensamento social da academia brasileira. Escreveu textos considerados referência no estudo das relações étnicoraciais no país, trabalhos que merecem a devida atenção. Afinal, este é um período em que o debate sobre as relações étnico-raciais vem fortemente à tona com o incentivo às ações compensatórias, de reconhecimento e valorização de políticas públicas afirmativas.

A teoria de Abdias Nascimento é o que o torna um intelectual público e formulador de políticas públicas, inclusive ações compensatórias de diversos motes, além de ter produzido toda uma obra de desconstrução de ideias como, por exemplo, a democracia racial. Foi uma personalidade negra não muito conhecida nos meios universitários brasileiros, apesar de ter sido um destacado intelectual. Por que pensamos desta forma? 


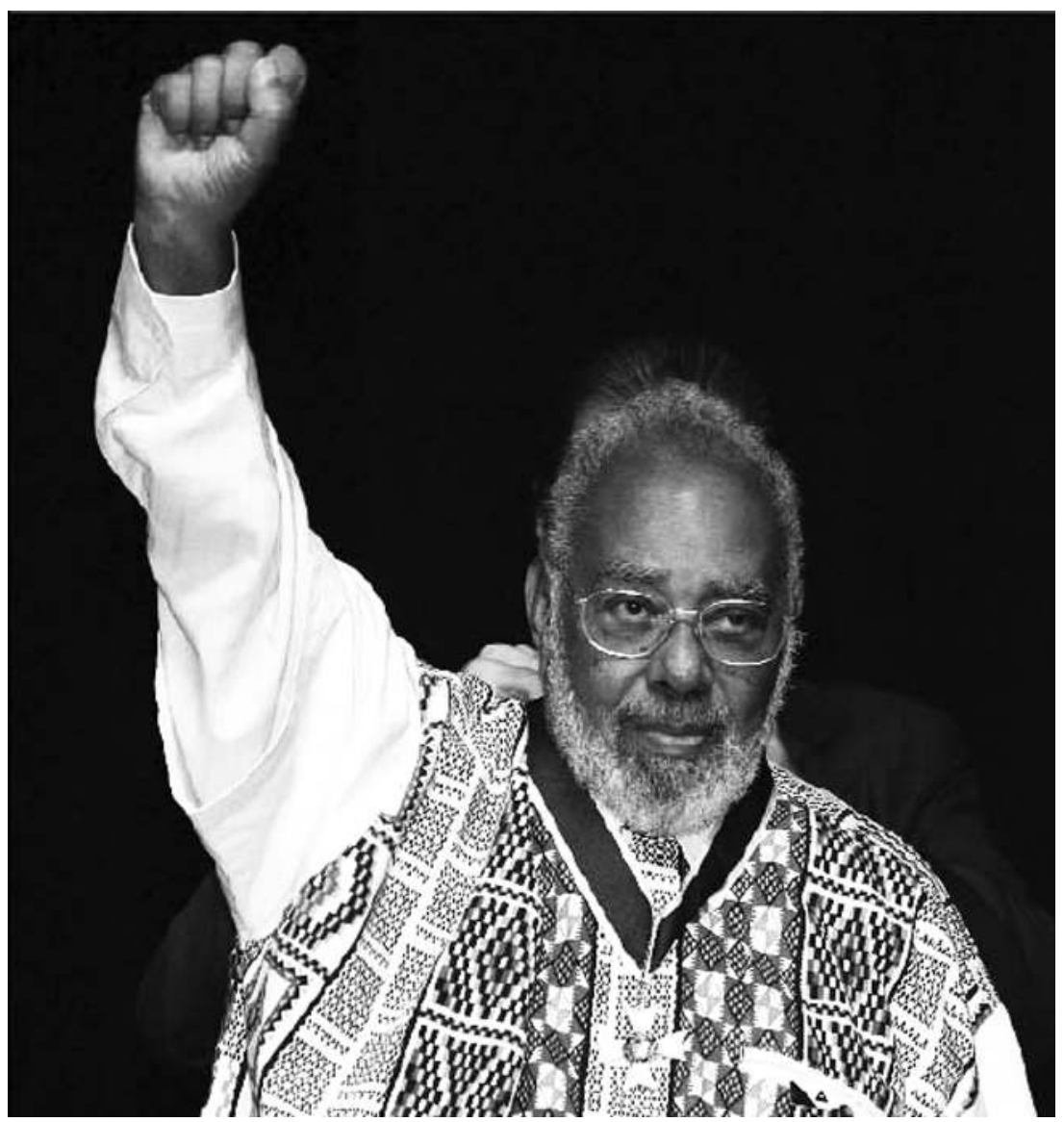

Abdias Nascimento.

Fonte: http://militanciaviva.blogspot.com.br/2011_05_01_archive.html

Ele e outros autores estão praticamente ausentes dos estudos e das referências bibliográficas do assunto na atualidade, não porque não tenham produzido conhecimento, mas por causa da histórica marginalização do negro no conservador meio acadêmico.

Resgatar aqui a vida intelectual de Abdias é um desafio de grande envergadura, visto que, nos meios universitários, apenas aqueles a quem a universidade reconhece como canônicos são aceitos pela academia, geralmente, os descendentes ou os próprios europeus. Uma espécie de troca de imagens, aqueles considerados intelectuais públicos, antigos pensadores e formuladores políticos agora são substituídos pelos acadêmicos puros, seres apolíticos que pretendem pesquisar e discutir em seminários sem afetar ou contribuir para realidade. Nei Lopes crê que Abdias do Nascimento foi o primeiro negro que realmente expôs, aqui e no exterior, uma imagem sem retoques ${ }^{1}$ da realidade da população negra no país.

A trajetória das ações afirmativas no Brasil, o racismo e as questões de classe que envolvem o problema, e a experiência da UERJ (Universidade do Estado do Rio de Janeiro) nestas políticas após uma década são os problemas gerais que nos colocaram a necessidade deste artigo. Darcy Ribeiro, Tzvetan Todorov, Peter Wolf, Lilian Schwarcz, Carlos Alberto Medeiros e Maria de Lourdes Fávero ajudarão a circundar o debate.

No Brasil, em níveis de classificações estatísticas gerais o Instituto Brasileiro de Geografia e Estatística - IBGE define raça/cor de acordo com a declaração fornecida pelas pessoas, no momento da entrevista, ou, no caso de concursos públicos, no ato da inscrição, segundo as seguintes opções: branca, preta, amarela, parda ou indígena.

1 Ver SEMOG, Ele; NASCIMENTO, Abdias. Abdias Nascimento: o griot e as muralhas. Rio de Janeiro: Pallas, 2006. 
Essa definição gera diversas polêmicas, pois no Brasil, a ideologia racista colabora para a resistência de negros e pardos na autoidentificação de sua cor/raça. A própria problemática cor e raça fora bastante discutida por Nascimento, Nogueira e Ribeiro, sendo este outro foco primordial da discussão do tema que faremos mais a frente.

Do ponto de vista histórico do conceito de raças, recorremos ao historiador Peter Wolf dentro da obra de Carlos Alberto Medeiros, pois oferece uma perspectiva ampla e histórica do conceito, inclusive, o atribuído à modernidade. Apenas com a expansão marítima e comercial e a chegada de portugueses no continente americano é que vai surgir em locais da África e Ásia distinções físicas entre os povos do velho continente e da parte deles com o restante do mundo. A noção de raça do século XVI permanece até a atualidade, contudo não mais em termos científicos, conforme se nota no senso comum (WOLF, apud MEDEIROS, 2004, p.33). "Atrevidos, sem crença na alma, vingativos, desonestos e dados à sensualidade", é o fragmento do livro da historiadora Lilia Schwarcz que pode ajudar a explicar fundamentos do racismo como forma de combate às ações afirmativas. Aspectos históricos recuperados por estes autores ajudam a vislumbrar a arquitetura do conceito de raça, o qual não pode mais ser explicado e justificado pela ciência, mas que permanece no imaginário popular e nas discussões que cercam nosso tema. Assim sendo, uma maneira de questionar as diversas formas de existência de fora do continente europeu, identificar os costumes de outros povos como estranhos e, dessa forma, inferiorizar as populações das novas posses territoriais conquistadas.

Ora, se o termo raça data do século XVI, por conseguinte, as teorias raciais surgem mais à frente, no século XVIII (SCHWARCZ, 2001, pp. 18-21), porém neste século estava mais ligada a concepção de grupos ou categorias de indivíduos de uma origem comum, não sendo postulados ainda por pesquisas científicas ou biológicas.

Se por um lado o iluminismo marca um contingente de reflexões acerca do liberalismo, por outro é neste movimento que processa a discussão intensa sobre o conceito das raças humanas. Através do pensamento racional iluminista é que se entendem as taxonomias originadas do reino animal e vegetal, conforme Carlos Alberto Medeiros nos mostra, até os seres humanos, provocando sensação tendenciosa. Os europeus aparecem em posição superior, denominados brancos, enquanto negros, amarelos e vermelhos são racializados como inferiores (MEDEIROS, 2004, p.34).

De acordo com diversas teses, os negros seriam descendentes de uma raça originalmente branca, que por ação do tempo e do clima teria enegrecido. Com isto, verifica-se o surgimento de diversas pesquisas e estudos que almejavam a comprovação de uma inferioridade da raça negra e superioridade dos brancos e a partir destas teorias, alastrar ideias de que os costumes, caráter, porte físico e a moral estavam diretamente ligados aos caracteres raciais (SANTOS, 2002, p. 56).

Com esta visão, o racismo científico se arvora no sentido de que há necessidade de uma Europa branca e civilizada ser modelo para a cultura no "novo mundo", sendo fundamentada pela biologia e até pela geologia numa espécie de racismo científico.

Estas ideais se espalham pelos campos da antropologia, no que se refere à fisiologia, muitas teses ligavam elementos físicos de indivíduos à sua conduta moral, logo a cor deixava de ser um qualitativo e ganha um caráter essencial, passando a revelar o ser de uma pessoa (SANTOS, 2002, p. 56).

Além da antropologia, tais concepções emergem na frenologia que se torna base política e ideológica das posições sociais que almejavam a eugenia. As premissas 
destes conceitos estavam calcadas na medida do tamanho do crânio, que revelaria o formato do cérebro, sendo este o órgão fundamental do corpo humano, dando possibilidades de mensurar a capacidade de cada raça, sua personalidade e caráter (SANTOS, 2002, p. 59).

Destas teorias e teses históricas é que as discussões atuais estão baseadas, mesmo que muitas dessas não possam mais ter comprovação científica, permanecem sendo pressupostos dos debates das ações afirmativas.

Vejamos outra introdução histórica do conceito de raças. Tzvetan Todorov ${ }^{2}$, historiador e pensador francês, aponta que a palavra racismo designa dois domínios diferentes da realidade: por um lado, um comportamento, muitas vezes de ódio e desprezo por pessoas ou grupo de pessoas com características físicas diferentes das nossas; por outro, uma ideologia, de uma doutrina referente às raças humanas.

$\mathrm{O}$ autor, na intenção de separar os diferentes sentidos desse conceito, atribui ao primeiro significado o termo de racismo, e ao segundo, o de racialismo. Afirma, então, que o racismo é um comportamento antigo e provavelmente universal, e o racialismo, enquanto doutrina científica é um conjunto de ideias que surge na Europa do século XVIII e se estende até meados do XX na sua busca de legitimação. Logo poderemos, entre outros aspectos, notar racialismo como uma espécie de racismo científico que se caracteriza por:

“a) considerar a existência de raças; b) postular a solidariedade das características físicas e morais; c) funcionar como uma doutrina de psicologia coletiva, hostil à ideologia individualista; d) bierarquizar as raças a partir do etnocentrismo; e) por fim, tendo estabelecido os "fatos" cientificos, estabelecer uma política racista, na conjunção da teoria (racialista) com a prática discriminatória" (TODOROV, 1993).

Considerando que, na história recente da humanidade, o racismo se verifica como uma polarização entre o superior e o inferior, essa polarização, refletiu-se nos últimos séculos no racismo que o branco pratica contra o negro. Ainda que as descobertas no campo da genética, bem como a sequência de algumas teses sobre a existência de diferentes raças na espécie humana, atualmente quase impossibilitam a legitimidade e a manutenção de teorias científicas de cunho racialistas.

Pode-se associar a isso ao nascimento e iminência dos debates sobre direitos humanos e a afirmação política, ideológica e cultural de sociedades historicamente marginalizadas, sobretudo após os processos de luta de descolonização e independência dos países africanos, fazendo cair por terra ideologias de dominação cultural, econômica e política formuladas por nações europeias para justificar o processo de expansão imperialista desde o final do século XIX. Contudo, permanece no seio dos debates e no imaginário popular os conceitos de raças já ultrapassados:

\section{(...)" embora a biologia contemporânea seja praticamente unânime na inadmissão de um} conceito cientifico de raça, isso não quer significar, que em termos de relações sociais, o termo "raça", não desempenhe um papel relevante no combate à discriminação e na promoção de instrumentos que visem à equalização de oportunidades"(IENSUE, 2010, p. 90).

2 Nascido em 1939 em Sófia, na Bulgária, e naturalizado francês, o filósofo e linguista Tzvetan Todorov é um dos mais importantes pensadores do século XX. Tzvetan Todorov é conhecido hoje principalmente por seu trabalho como ensaísta, historiador e filósofo. Da Conquista da América, Nós e os outros ao espírito do Iluminismo, seus textos se tornaram clássicos. 
Nossa sociedade conviveu mais de trezentos anos com a escravização de negros e indígenas, submetida, ainda, à divisão social entre trabalho manual e intelectual, grosso modo, na dicotomia entre trabalho escravo (predominantemente negro) e trabalho livre (predominantemente branco). Esta dicotomia, sem dúvidas, gerou marcas de exclusão e da discriminação impressas nas diferentes instituições, fosse a família, a igreja, ou, mesmo no caso que nos interessa particularmente, as escolas superiores/ universidades. Desde a criação das primeiras cadeiras de Anatomia - no Rio de Janeiro - e de Cirurgia - no Rio e na Bahia, primeiros cursos superiores desarticulados e distintos, com a vinda da família real portuguesa em 1808, os cursos de nível superior são espaços onde o privilégio das classes dominantes continua se manifestando quase que de modo estrutural ${ }^{3}$.

As ações afirmativas foram implantadas em diversos países de tradição democrática ${ }^{4}$, contudo, ainda desperta em países considerados referências como Estados Unidos, França e até países, como Índia e Austrália, têm uma série de debates e polêmicas políticas nesse sentido. Logo, a discussão sobre políticas afirmativas no cenário brasileiro ainda se apresenta em patamar de discussão mais genérico e menos profundo, ou seja, com necessidade de se limpar o campo e traçar perspectivas conceituais no que se refere às raças e a democracia racial.

A contribuição teórica para esta discussão perpassa primeiramente por uma discussão étnico-racial no país, nesta linha é preciso considerar diversos autores, sobretudo, as teorias de pensadores engajados, como é o caso de Abdias do Nascimento, professor da instituição (UERJ) que anos depois adotou as políticas que um dia ele propusera na Câmara Federal.

Motivado por uma constante inquietação na busca por referenciais analíticos que propusessem visões alternativas sobre a realidade afrodescendente no Brasil e na América Latina, Nascimento é destacado militante nos diversos movimentos sociais contemporâneos do século XX, porém seu renome se expande até a academia de fama nacional e internacional, fornecendo instrumentos de análise para ajudar na compreensão de uma enorme lacuna deixada no debate sobre o pensamento social brasileiro.

O professor Abdias do Nascimento é reconhecido internacionalmente como um dos principais pensadores pan-africanistas ${ }^{5}$. Nesse sentido, seus escritos foram decisivos para avançar a premissa teórica de que na América Latina se formou um sistema de dominação étnico-racial e socioeconômico específico, baseado precisamente na "mes-

3 As ações afirmativas possuem, no Brasil, uma história anterior às medidas implementadas pelos governos federal e estaduais a partir dos anos 2000. Apesar de pouco conhecidas e, na realidade, não encaradas dessa maneira, Carlos Alberto Medeiros cita que há exemplos na legislação brasileira, já na década de 30, de discriminações positivas que visavam garantir a participação majoritária de trabalhadores brasileiros nas empresas em funcionamento, a chamada Lei dos Dois Terços. Outros exemplos são leis que garantem emprego a portadores de deficiência, a participação de mulheres na lista de candidatos dos partidos, fora outras medidas que beneficiam crianças, jovens, idosos, micro e pequeno empresários (MEDEIROS, pp. 123-124). 4

5 Abdias do Nascimento é Professor Emérito da Universidade do Estado de Nova York e Doutor Honoris Causa pelas Universidades de Brasília, Federal e Estadual da Bahia, Estado do Rio de Janeiro, e Obafemi Awolowo da Nigéria. Hoje ele é indicado oficial ao Prêmio Nobel da Paz em função de sua defesa consistente, desde o século passado até hoje, dos direitos civis e humanos dos afrodescendentes no Brasil e no mundo. Vem sendo agraciado com honrarias nacionais e internacionais, como por exemplo, o Prêmio Mundial Herança Africana do Centro Schomburg para Pesquisa da Cultura Negra, Biblioteca Pública de Nova York (2001); o Prêmio Toussaint Louverture (2004) e o Prêmio Direitos Humanos e Cultura da Paz (1997), ambos da Unesco; e o Prêmio de Direitos Humanos da ONU (2003). A Universidade Obafemi Awolowo, de Ilé-Ifé, Nigéria, outorgou-lhe, em 2007, o título de Doutor em Letras, Honoris Causa. O Conselho Nacional de Prevenção da Discriminação, do Governo Federal do México, outorgou a Abdias do Nascimento o seu prêmio em reconhecimento à contribuição destacada à prevenção da discriminação racial na América Latina (2008).

Fonte: http://www.ipeafro.org.br/home/br/personalidades. Acessado em 02/01/2015. 
tiçagem programada" entre raças e etnias situadas em posições fixas de inferioridade e de superioridade. Com uma teoria autêntica, Abdias foi um pensador social crítico à estrutura social brasileira que, segundo ele, era alicerçada no processo escravagista.

A condição social do negro no Brasil deve ser levada em consideração para esta análise, não só em termos numéricos ou estatísticos da atualidade, mas cabe observar a historicidade e importância do negro como ator social relevante à sociedade brasileira, especialmente a crítica a um modelo social construído a partir de hierarquias que também têm características raciais e poderão contribuir para a elucidação e compreensão das demandas sociais em geral, e raciais em especial.

Abdias Nascimento em seus escritos acreditava que a democracia brasileira superararia seu racismo estrutural apenas quando se tornasse uma sociedade plurirracial.

[...] "ou ela é democrática para todas as raças e lhes confere igualdade econômica, social e cultural, ou não existe uma sociedade plurirracial democrática. À hegemonia da 'raça' branca se contrapõe uma associação livre e igualitária de todos os estoques raciais" (NASCIMENTO, 1978, p. 37).

Em O genocidio do negro brasileiro, Abdias do Nascimento critica os efeitos que a ideologia da democracia racial imposta aos afrodescendentes brasileiros, mas também a toda sociedade, uma vez que seus efeitos políticos, psicológicos e ideológicos podem ser percebidos atualmente. $\mathrm{O}$ conceito de democracia racial erigiu-se no Brasil a partir de especulações, com o apoio das chamadas ciências históricas, e refletia determinada relação concreta na dinâmica da sociedade brasileira: que negros e brancos têm uma convivência harmônica, e que desfrutam de oportunidades iguais de existência, sem interferência de origens raciais ou étnicas. Ideologia esta formulada por Gilberto Freyre como se pudesse haver um luso-tropicalismo, onde a ideia de um Brasil sem raças e problemas raciais pudesse florescer, sem ações compensatórias para com as populações um dia escravizadas e seus descendentes.

"Devemos compreender "democracia racial" como significando a metáfora perfeita para designar o racismo estilo brasileiro: não tão óbvio como o racismo nos Estados Unidos e legalizado qual o apartheid da África do Sul, mas eficazmente institucionalizado dos niveis oficiais de governo assim como difuso no tecido social, psicológico, econômico, político e cultural da sociedade do país. Da classificação grosseira dos negros como selvagens e inferiores, ao enaltecimento das virtudes da mistura de sangue como tentativa de erradicação da "mancha negra"; da operatividade do "sincretismo" religioso; à aboliçâo legal da questão negra através da Lei de Segurança Nacional e da omissão censitária - manipulando todos esses métodos e recursos - a história não oficial do Brasil registra o longo e antigo genocídio se vem perpetrando contra o afrobrasileiro. Monstruosa máquina ironicamente designada democracia racial que só concede aos negros um único "privilégio": aquele de se tornarem brancos, por dentro e por fora. A palavra senha desse imperialismo da brancura, e do capitalismo que lhe é inerente, responde a apelidos bastardos como assimilação, aculturação, miscigenação; mas sabemos que embaixo da superfície teórica permanece intocada a crença na inferioridade do africano e seus descendentes". (NASCIMENTO, 1978, p. 93)

Adeptos desta teoria expuseram ao mundo um novo modelo de sociedade, baseada na superioridade racial portuguesa, leia-se branca, e em sua importância à concepção 
de uma civilização avançada, fundada na mestiçagem que, neste caso, é aquela que embranquece e assimila as outras culturas.

Conforme demonstra Abdias do Nascimento, o luso-tropicalismo é a ideologia que levou a elite intelectual a crer que os portugueses tiveram o mérito de colonizar o Brasil e parte do continente africano, sendo este a base política, histórica e ideológica da teoria da democracia racial.

Gilberto Freyre cunhou um conceito que visava racionalizar as relações raciais no país. O termo morenidade seria o maior exemplo desta racionalização que tem como objetivo "o desaparecimento inapelável do descendente de africano, tanto fisicamente quanto espiritualmente, através do malicioso processo de embranquecer a pele negra e a cultura do negro" (NASCIMENTO, 1978).

Com essa crítica ao pensamento social conservador, que via o negro como componente menor da identidade nacional, Abdias desconstrói e refuta a ideia de que o africano seria um "co-colonizador" do Brasil sem levar em conta sua condição de escravo, principiando influências culturais sobre o processo de formação da sociedade brasileira. Essa perspectiva teria, como ônus, a responsabilização dos africanos, juntamente com os portugueses devido à sistemática erradicação das populações indígenas, o que, segundo o autor, não se verifica. Abdias do Nascimento percebia que o genocídio dos povos indígenas é exclusivamente responsabilidade dos colonizadores, portanto portugueses.

A miscigenação proposta por Freyre pode ser considerada o cerne do debate das políticas afirmativas no momento em que as argumentações contrárias às políticas compensatórias se anteparam em uma noção de negação das contradições raciais e de cor. Exemplo maior é o livro, Não somos racistas $(2006)^{6}$ de Ali Kamel, diretor de jornalismo da Rede Globo. Reparando que o livro é lançado em 2006 no auge dos debates e disputas acerca das políticas compensatórias. Grosso modo, a obra sustenta a tese de que as cotas são políticas públicas incoerentes com a nossa história criando o risco de dividir o país entre brancos e negros, e criarem um ambiente propício ao ódio racial. Kamel é um defensor ardente da democracia racial brasileira e defende que há um grande perigo em "obrigar" os brasileiros a se declararem negros ou indígenas. O próprio título do livro ressalta que o racismo não é preponderante na sociedade brasileira, aliás o título se completa da seguinte forma: uma reação aos que querem nos transformar numa nação bicolor" - Kamel afirma que o racismo não se justifica em nossa sociedade e que as instituições públicas não o reforçam de modo algum, além de negar que somos uma nação bicolor. Ou seria multicolor?

O fato é que a discussão mais uma vez está no centro do debate da democracia racial, que Abdias tenta desconstruir em duas das suas principais obras O Genocídio do Negro Brasileiro e O quilombismo.

"A metarraça significaria o além-raça, suposta base de consciência brasileira. Atingiríamos neste ponto do nosso desenvolvimento demográfico uma sintese suprema: a morenidade metarracial, oposta aos conceitos fornecidos por arianismo e negritude" (NASCIMENTO, 1978 p. 44).

Está nas teses de Abdias Nascimento boa parte da problemática atual sobre o sistema de ações afirmativas no país, desde os críticos que embasados na teoria da

6 KAMEL, Ali. Não somos racistas: uma reação aos que querem nos transformar numa nação bicolor. Rio de Janeiro: Nova Fronteira, 2006. 
democracia racial, até as obras mais recentes que visaram aprofundar a discussão no sentido de defender tal política.

O processo de genocídio do negro, diz respeito à ideologia do branqueamento que, para Abdias, era um dos pontos centrais acerca da formação social no Brasil. A elite intelectual dominante ao eleger o mulato como símbolo de brasilidade e sustentáculo da "democracia racial", estabelece o primeiro degrau na escala daquilo que chama de branquificação sistemática do povo brasileiro.

O mulato é o marco que assinala o início da liquidação da raça negra no Brasil. O autor identifica um processo progressivo de clareamento da população brasileira, com o avanço do elemento mulato e o sistemático desparecimento do negro. Contudo, não se percebe qualquer tipo de vantagem no status social, pois a posição do mulato se equivale àquela do negro: ambos são vítimas de igual desprezo, idêntico preconceito e discriminação, cercado pelo mesmo desdém da sociedade brasileira institucionalmente branca.

Tal processo de branquificação ou branqueamento é apontado pelo autor como pilar do que nomeia como racismo mascarado, que nos parece fundamental para esta análise. O objetivo final desta ideologia sutil definida como mestiçagem, que tem na miscigenação sua vertente biológica e no sincretismo cultural sua vertente política. Munanga (2006) demonstra que tal processo desembocaria numa sociedade unirracial e unicultural.

"Uma tal sociedade seria construida segundo o modelo hegemônico racial e cultural branco ao qual deveriam ser assimiladas todas as outras raças e suas respectivas produçôes culturais. $O$ que subentende o genocídio e o etnocídio de todas as diferenças para criar uma nova raça e uma civilização, ou melhor, uma verdadeira raça e uma verdadeira civilização brasileiras, resultantes da mescla e da sintese das contribuições dos stocks raciais originais. Em nenhum momento se discutiu a possibilidade de consolidação de uma sociedade plural em termos de futuro, já que o Brasil nasceu historicamente plural" (MUNANGA, 2006 p. 97).

Propunham os setores dominantes no país, principalmente, no final do século XIX e começo do século XX, a construção de uma sociedade na qual o domínio hegemônico da cultura de matriz europeia e, por consequência branca, seria o referencial que orientaria a formação dessa sociedade egressa do regime escravocrata. Logo, o Brasil não teria nenhuma característica multirracial ou multicultural, conforme se nota na narrativa de Kamel.

O fato de não se discutir o termo raça no país tem sido agravante barreira na implementação e, atualmente, no aprofundamento das políticas afirmativas enquanto políticas públicas. Até mesmo a população negra no Brasil é, frequentemente, impedida, pelos tabus erigidos através de certa proibição, da discussão sobre raça. Abdias do Nascimento já demonstra, há quase 30 anos, que a camada intelectual dominante e os setores políticos consideram qualquer movimento de conscientização afro-brasileira como ameaça ou agressão retaliativa movida por sentimento de vingança. Aponta também que em determinadas ocasiões os negros são condenados, pois pretendem impor ao país uma suposta superioridade racial negra, fato que também não se verifica.

Abdias do Nascimento, na visão de Florestan Fernandes, contribui de forma evidente no que diz respeito à proposição de uma série de medidas que poderiam configurar a construção de um novo quadro social. "Essas sugestões demarcam a diferença essencial que existe entre uma pseudodemocracia racial e o que deveria ser uma sociedade plurirracial 


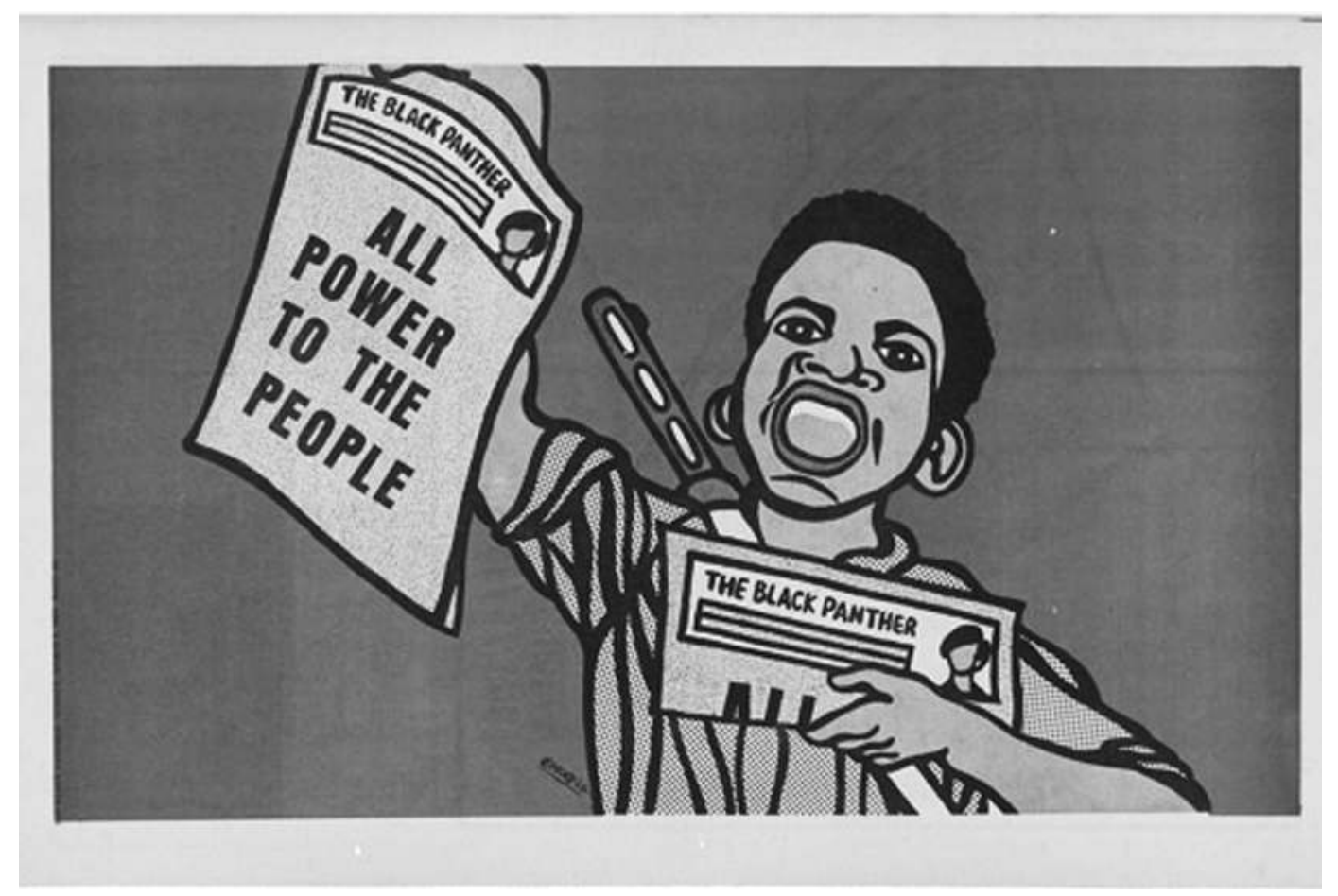

"Todo poder ao povo". Cartaz dos Panteras Negras. Fonte: http://etnicomhum. blogspot.com.br/2013/04/abdias-do-nascimento-quem-foi.html

democrática" (1978, p.21). A tentativa de superação de uma condição de desigualdade e opressão encontra-se na base das reivindicações e proposições apresentadas pelo autor.

"Qualquer esforço por parte do afro-brasileiro esbarra neste obstáculo. A ele não se permite esclarecer-se e compreender a própria situação no contexto do país; isso significa, para as forças no poder, ameaça à segurança nacional, tentativa de desintegração da sociedade brasileira e unidade nacional" (NASCIMENTO, 1978 p. 78).

Ao que parece há um objetivo não expresso no âmbito da democracia racial. O que Abdias chama de processo de um racismo mascarado é negar ao negro a possibilidade de se autodefinir, desfalcando-lhe os meios de identificação racial. É exatamente numa espécie de negação do direito do autorreconhecimento identitário que se encontra a chave da dominação e exploração da população negra no Brasil, uma vez que serve como fator que imobiliza e desmotiva qualquer tipo ou grau de organização que vise questionar a real condição deste segmento.

O Estado brasileiro construiu durante longo período uma imagem que visou sempre negar e suprimir a perspectiva racial como fator determinante em sua dinâmica social, política e pública. Contudo, segundo Abdias, criou-se assim um modelo que esteve e acreditamos que continua estando na contramão da realidade nacional cotidiana.

A situação desfavorável e desigual a que foram submetidos os afro-brasileiros ao longo da história brasileira não é apresentada nem pela bibliografia mais contemporânea ao cenário internacional. A partir da elite política do país se afirma, com certa veemência, a importância de se constituir uma nação de acordo com um conjunto de relações socais e raciais harmônicas, inclusive buscando colocar a sociedade brasileira como exemplo de inexistência de conflitos raciais. Neste rastro é que não se justificaria a implantação de políticas afirmativas com perspectivas parecidas de 
países centrais ou até das experiências mais novas como se verifica em países como Austrália e Nova Zelândia.

Abdias demonstra que desde a classificação grosseira dos negros como seres selvagens e, por isso inferiores, até o enaltecimento das virtudes da mistura de sangue como tentativa de erradicação da mancha negra; da capacidade operacional do sincretismo religioso, à abolição legal da questão racial através de medidas legais como a omissão censitária, as técnicas de invisibilizar o negro e seus dramas na sociedade brasileira tem se aprimorado e se pautado em diversas teorias políticas e sociais.

"Monstruosa máquina ironicamente designada 'Democracia Racial' que só concede aos negros um único privilégio: aquele de se tornarem brancos, por dentro e por fora". Com esta afirmativa podemos perceber que tipo de debate temos traçado em nossos dias atuais, visto que a argumentação acerca do tema das políticas afirmativas passa pela democracia racial e pela crítica do movimento negro a ela, sendo boa parte teoria produzida por Abdias Nascimento.

O imperialismo da brancura, termo utilizado pelo autor, marcado pelo capitalismo que lhe é inerente, nos permite concluir que o racismo é parte integrante do sistema capitalista. Para ele, o racismo estrutural e institucional brasileiro, não pode ser entendido e pesquisado descolado do sistema político e econômico. Abdias em seus ensaios no livro O Quilombismo, afirma:

"De uma coisa estava convencido: que uma coerência fundamental e uma unidade intima entrelaçavam os ensaios em si; e que essa essência unificadora se exprimia no objetivo comum de revelar a experiência dos africanos no Brasil, assim como na tentativa de relacionar dita experiência aos esforços das mulheres e dos homens negro-africanos de qualquer parte do mundo em luta para reconquistar sua liberdade e dignidade humana, assumindo por esse meio o protagonismo da sua própria história. (NASCIMENTO, 1980, p. 13)

[...] os homens e as mulheres da África, e de descendência africana, têm tido uma coisa em comum - uma experiência de descriminação e humilhação imposta sobre eles por causa de sua origem africana. Sua cor foi transformada tanto na marca como na causa de sua pobreza, sua bumilhação e sua opressão" (NEYRERE, apud NASCIMENTO, 1980, p. 17).

A democracia racial está ligada a conceitos e termos do tipo assimilação, aculturação, miscigenação, que camuflam, sob uma superfície teórica, a crença intocada na inferioridade dos afro-brasileiros e seus descendentes.

É possível perceber na obra O genocídio do negro brasileiro que Abdias do Nascimento opera sobre as categorias mestiçagem e genocídio como fundamentais para sua pesquisa sobre a condição social, econômica e política do negro brasileiro. A mestiçagem pode ser entendida como a imbricação entre a miscigenação, uma forma biológica de intercurso racial, e uma espécie de sincretismo cultural que formaria, médio prazo, uma sociedade unirracial e unicultural. Nesta mestiçagem está grande parte do aporte teórico da democracia racial, consequentemente, do embasamento do debate que permeia as ações afirmativas.

Especificamente, observando o caso brasileiro, pode-se perceber que a ideia de morenidade é fator que põe a democracia racial como teoria central que pode conferir o status de pertencimento a uma identidade nacional, logo a mestiçagem submete a diversidade dos componentes culturais do país à homogeneidade expressa pelo sincretismo. No entanto, para Abdias é necessário justamente negar os termos da 
morenidade, pois nele que se encontra o ápice do processo ao qual ele define como genocídio. Isto se dá através da implementação organizada de uma mestiçagem programada, conforme dito anteriormente, que objetiva eliminar sistematicamente o elemento negro da dinâmica social brasileira.

"Podemos ler as páginas da história da humanidade abertas diante de nós, e a lição fundamental que nos transmitem é de uma enorme fraude teórica e ideológica articulada para permitir que a supremacia ário-euro-norte-americana pudesse consumar sua imposição sobre nós". (NASCIMENTO, 1980, p. 22).

O racismo estrutural espraiado na sociedade brasileira se faz presente nas instituições e políticas públicas, neste quesito, outra vez, Abdias se coloca de forma pioneira:

"Além dos órgãos de poder - o governo, as leis, o capital, as forças armadas, a politica - as classes dominantes brancas têm à sua disposição poderosos implementos de controle social e cultural: o sistema educativo, as várias formas de comunicação de massa - a imprensa, o rádio, a televisão - a produção literária. Todos esses instrumentos estão a serviço dos interesses das classes no poder e são usados para destruir o negro como pessoa e como criador e condutor de uma cultura própria”. (NASCIMENTO, 2002, p. 142).

Diante destas afirmações e dos referenciais que nos apoiamos, pode ser possível sustentar que há barreiras sociais e também racialmente seletivas, que impedem a mobilidade social de parcelas negras da população e os mesmos de acessar mecanismos fundamentais na construção da cidadania nacional.

Negro, bom escravo, mau cidadão? (1977), publicado na Série Temas Brasileiros, é o segundo livro de Clóvis Moura pela Editora Conquista, do Rio de Janeiro; em 1972, já havia publicado por ela, na mesma séria, a segunda edição de Rebelióes. Clóvis Moura traz um enfoque mais sociológico do problema do negro sem prescindir de seu caráter histórico.

Ele se debruça sobre o problema da exclusão do negro de cargos mais altos ou de maior envergadura na sociedade, isto é, a marginalização do negro na sociedade competitiva e de classes. A problemática apresentada nos empurra para a seguinte pergunta: qual é a função, na sociedade capitalista de classes, dos estereótipos em relação ao negro? Estes estereótipos classificariam o negro como mau cidadão, ou seja, despreparado para a liberdade que lhe foi atribuída no pós-abolição e desta maneira contraria a sua postura benevolente no eito, quando escravo.

Caracterizam-se, então, julgamentos morais sobre o comportamento do negro - bom e mau - segundo Moura, é a consciência reflexa da classe escravista na sociedade burguesa, pois são definidas de acordo com os interesses de manter os negros à margem do processo de produção. Desta forma, constitui-se uma imagem abstrata e caricata dos brancos sobre o negro:

(...) "não tem condições de desfrutar da liberdade, pois dissipa-a na cachaça, no amor livre e na maconha. Para estes estratos, o negro, desde que conseguiu livrar-se do cativeiro vem demonstrando como, por uma questão de inferioridade congênita, incurável, não tem condições de competir com o branco, que é visto como membro de uma raça mais inteligente, limpo, culto, 
que pauta o seu comportamento por padróes morais mais elevados aos quais o negro não poderá chegar"(MOURA, 1978, p.19).

\section{Conclusão}

A situação social do negro brasileiro é destacada nas obras analíticas da realidade social, sejam elas de cunho sociológico ou estrutural, sejam em anuários estatísticos e materiais mais empíricos. Os autores citados têm produções de análises mais estruturais do negro na sociedade brasileira, observando-o em diversos momentos da história nacional e produzindo uma interpretação da realidade para aquele determinado setor social.

Apesar de matrizes analíticas distintas, os autores convergem em pontos de observação sobre as barreiras que o racismo estrutural impõe a negras e negros nesta sociedade. Ambos versam sobre o caráter estrutural do racismo brasileiro e as barreiras construídas por este fato, que deve ser verificado empiricamente na sub-representação da população negra em diversos espaços sociais. Isto, quer dizer que instituições como escolas, universidades, poderes legislativos, judiciário e executivo, assim como altos postos de empregos privados têm uma proporção de negros menores do que a representação deste grupo na sociedade.

Nessa perspectiva, concluímos que as políticas compensatórias para população negra no país são um mecanismo de combate ao racismo, mas não garantem efetivamente a derrota deste ao entendermos seu caráter estrutural. A democracia racial proposta e "inventada" por Freyre, não pode se concretizar. Nascimento é quem propõe uma sociedade plurirracial, diante da compreensão que o racismo é estrutural na sociedade brasileira, por isso esta formulação deve pressupor não apenas ações compensatórias para o povo negro, pois estas alteram a correlação de forças, mas ainda não podemos afirmar que são capazes por si só de modificar a estrutura societária nacional, portanto, de derrotar o racismo brasileiro.

\section{Referências bibliográficas}

FERNADES, Florestan. A integração do negro na sociedade de classes: (o legado da "raça branca", volume I) - 5. Ed. - São Paulo: Globo 2008.

FERNANDES, Florestan. A Integração do Negro na Sociedade de Classes. São Paulo: Dominus-USP, 1965.

GUIMARÃES, Antonio Sérgio. Classes, Raças e Democracia. São Paulo: Editora 34. 2002.

Moura, Clóvis. Rebeliões da senzala - quilombos, insurreições, guerrilhas. Mercado Aberto, Porto Alegre, 1988 (1a edição: 1959)

. O negro: de bom escravo a mau cidadão? Editora Conquista, RJ, 1977 . Sociologia do negro brasileiro. São Paulo: Ática, 1988. . História do negro brasileiro. São Paulo: Ática, 1989.

MUNANGA, K. O Anti-racismo no Brasil. In: MUNANGA, K. (org.). Estratégias e políticas de combate à discriminação racial. São Paulo: Edusp, p.79-111, 1996. . Rediscutindo a Mestiçagem no Brasil: identidade nacional versus identidade negra. Pertópolis, RJ: Vozes, 1999 
NASCIMENTO, Abdias do. O Genocídio do Negro Brasileiro. Rio de Janeiro: Paz e Terra, 1978.

. O quilombismo. Petrópolis: Editora Vozes, 1980.

. (org.). O Negro Revoltado. 2a Ed. Rio de Janeiro: Nova Fronteira, 1982.

NOGUEIRA, Oracy. Tanto preto quanto branco: estudo de relações raciais. São Paulo: T. A. Queiroz, 1985.

. O povo brasileiro - A formação e o sentido do Brasil. São Paulo: Companhia das Letras: 2006.

SCHWARCZ, Lilia Moritz. Racismo no Brasil. São Paulo: Publifolha, 2001.

SILVA JR., Hédio. Direito de Igualdade Racial: Aspectos Constitucionais, Civis e Penais. São Paulo: Juarez de Oliveira, 2002.

Artigo recebido em junho de 2015 e aprovado para publicação em dezembro de 2015. 